\title{
ARTÍCULOS
}

\section{SEXUALIDAD Y RELIGIÓN EN EL TARDOFRANQUISMO. LA RECEPCIÓN DE LA HUMANAE VITAE EN ESPAÑA Y LA CRISIS DE AUTORIDAD DE LA IGLESIA*}

\author{
Sexuality and Religion in Late Francoism. The Reception of Humanae Vitae \\ in Spain and the Crisis of Authority in the Church
}

\author{
Mónica García Fernández \\ Universidad del País Vasco (UPV/EHU) \\ monica.garciaf@ehu.eus \\ Orcid: 0000-0002-5962-4606
}

Cómo citar este artículo/Citation:

Mónica García Fernández, "Sexualidad y religión en el tardofranquismo. La recepción de la Humanae Vitae en España y la crisis de autoridad de la Iglesia”, Hispania Nova, 19 (2021): 255 a 290.

DOI: https://doi.org/10.20318/hn.2021.5882

Copyright: (C) HISPANIA NOVA es una revista debidamente registrada, con ISSN 1138-7319 y Depósito Legal M 9472-1998. Los textos publicados están -si no se indica lo contrario- bajo una licencia Reconocimiento-Sin obras derivadas 3.0 España de Creative Commons. Puede copiarlos, distribuirlos y comunicarlos públicamente siempre que cite su autor y la revista y la institución que los publica y no haga con ellos obras derivadas. La licencia completa se puede consultar en: http://creativecommons.org/licenses/by-nd/3.0/es/deed.es

Resumen: El objetivo de este artículo es analizar el contexto en el que se publicó la encíclica Humanae vitae (1968) de Pablo VI y su recepción en España. Se trata de explorar sus antecedentes e impacto en el marco del Concilio Vaticano II y también del llamado "desenganche" de la Iglesia en el tardofranquismo. La controversia que se generó cuestionó la propia autoridad moral de la Iglesia. Además, se inserta en un contexto en el que se estaba produciendo una importante transformación en la concepción católica de la sexualidad, ligada asimismo a un vivo debate sobre el control de la natalidad en el que la popularización de la "píldora" tuvo gran peso.

Palabras clave: sexualidad, religión, tardofranquismo, control de la natalidad, píldora
Abstract: This paper analyses the context of Paul VI's encyclical Humanae Vitae (1968) and its reception in Spain. The aim is to explore its background debates and impact in relation to the Second Vatican Council and also to the so-called "disengagement" of the Church from the Franco Regime in its final years. The controversy that surrounded the document put into question the Church's moral authority. Furthermore, it is understood in the context of a substantial change in the catholic definition of sexuality. This is also linked to a heated debate about birth control in which the popularization of the "pill" had a significant influence.

Keywords: sexuality, religion, late Francoism, birth control, pill 


\section{INTRODUCCIÓN}

No cabe duda de que 1968 es un año particularmente emblemático para la historia contemporánea, pero también es clave para entender la trayectoria del catolicismo y el proceso de secularización en Occidente. En julio de este año se publica la encíclica Humanae vitae, en la que Pablo VI condena los anticonceptivos. Si bien esta decisión estaba en línea con el discurso tradicional del Vaticano, se trataba sin embargo de la culminación de un periodo de debate en el que parecía que iba a producirse una liberalización, enmarcado en la controversia que había desencadenado la "píldora" anticonceptiva, cuya popularidad y ventas no habían dejado de crecer. Según afirman distintas investigaciones, este momento marca, no solo el fin del itinerario aperturista del Concilio Vaticano II en materia de sexualidad, sino también una brecha en el seno de la Iglesia ${ }^{1}$. De ese modo, una parte de la comunidad católica se distanció de la ortodoxia, adoptando ideas favorables al control de la natalidad y promoviendo una transformación significativa en la forma en que se entendía la sexualidad.

El objetivo de este artículo es analizar el contexto en el que se publicó la encíclica y su recepción en España, valorando su impacto en la definición católica del amor sexual, así como en la crisis de autoridad moral de la Iglesia. Comenzaré situando la Humanae vitae en su contexto histórico y analizando sus antecedentes, que vienen determinados tanto por la popularización de la píldora, como también por los cambios en la concepción católica de la sexualidad en el marco del Concilio Vaticano II. Pasaré después a estudiar el impacto de la encíclica y su recepción en España.

En los últimos años este tema viene siendo objeto de una interesante historiografía, realizada tanto en el marco de las relaciones entre sexualidad y religión, como en el de la historia del control de la natalidad y, más concretamente, en la de la píldora $^{2}$. En España destacan especialmente los trabajos de Agata Ignaciuk y Teresa

\footnotetext{
* Esta investigación se inscribe dentro del Grupo de Investigación "La experiencia de la sociedad moderna en España, 1870-1990" y ha sido posible gracias a una ayuda de contratación para la especialización de personal investigador doctor concedida por la UPV/EHU en su convocatoria de 2019.

${ }^{1}$ Alana Harris, ed., The Schism of '68: Catholicism, Contraception and Humanae Vitae in Europe, 19451975 (Palgrave MacMillan, 2018); David Geiringer, The Pope and the Pill: Sex, Catholicism and Women in Post-War England (Manchester University Press, 2019).

${ }^{2}$ Ibidem; Laura Marks, Sexual Chemistry: A History of the Contraceptive Pill (Yale University Press, 2010); Karina A. Felitti, La revolución de la píldora: sexualidad y política en los sesenta (Buenos Aires:
} 
Ortiz sobre este fármaco, que incluyen un análisis del discurso médico, del debate en los medios de comunicación $\mathrm{y}$, aunque en menor medida, también de la controversia religiosa ${ }^{3}$. Será este último aspecto en el que me centraré de forma particular en este artículo. Por tanto, no me interesa examinar la discusión sobre la píldora o su difusión en nuestro país, ni los argumentos en favor o en contra de la misma, aunque estos son aspectos clave a tener en cuenta, sino su importancia en la construcción de una moral sexual católica que experimentó importantes cambios en los años sesenta y setenta.

Es importante señalar que este proceso se sitúa tanto en el contexto de los cambios transnacionales que experimentó el discurso católico como consecuencia del Concilio Vaticano II, como también en el marco del llamado "despegue" o "desenganche" de la Iglesia en nuestro país ${ }^{4}$. Es de sobra conocido el impacto del aggiornamento en España. Asimismo, también se ha llamado la atención sobre la rápida secularización que tuvo lugar en nuestro país desde los años sesenta ${ }^{5}$. Sin embargo, queda aún por estudiar la importancia del factor sexual en este proceso ${ }^{6}$. Algunas investigaciones sobre sexualidad y religión centradas en otros países destacan precisamente la trascendencia de la revolución sexual como un elemento esencial para entender la secularización de las sociedades occidentales tras la segunda guerra

Edhasa, 2012); Deirdre Foley, “'Too Many Children?' Family Planning and Humanae Vitae in Dublin, 1960-72", Irish Economic and Social History, 46, 1 (2019): 142-160, doi: https:/doi.org/10.1177/0332489319880677; Agata Ignaciuk y Laura Kelly, "Contraception and Catholicism in the Twentieth Century: Transnational Perspectives on Expert, Activism and Intimate Practices”, Medical History, 64, 2 (2020): 163-172, doi: https://doi.org/10.1017/mdh.2020.1

3 Agata Ignaciuk y Teresa Ortiz, Anticoncepción, mujeres y género. La "píldora” en España y Polonia (1960-1980) (Madrid: La Catarata, 2016); Agata Ignaciuk, "Love in the Time of El Generalísimo: Debates About the Pill in Spain Before and After Humanae Vitae", ed. por Alana Harris, The Schism of '68: Catholicism and Humanae Vitae in Europe, 1945-1975 (Palgrave MacMillan, 2018), 229-271.

4 Por mencionar solo algunos trabajos, destacan los de Manuel Ortiz Heras y Damián A. González, coords., De la cruzada al desenganche (Madrid: Sílex Ediciones, 2011); Feliciano Montero, La Iglesia: de la colaboración a la disidencia (1956-1975) (Madrid: Ediciones Encuentro, 2009); del mismo autor es el monográfico "El 'despegue' de la Iglesia", Historia del Presente, 10, 2 (2007).

5 Julio de la Cueva Merino, "La secularización tranquila. Procesos de secularización bajo el franquismo (1960-1975)", ed. por Julio de la Cueva, Miguel Hernando de Larramendi y Ana I. Planet, Encrucijadas del cambio religioso en España. Secularización, cristianismo e islam, (Granada: Comares, 2018), 31-54; Alfonso Pérez-Agote, Cambio religioso en España: los avatares de la secularización (Madrid: Centro de Investigaciones Sociológicas, 2012).

${ }^{6}$ Una excepción es el artículo de Agata Ignaciuk, "Love in the Time of El Generalísimo...”. Sí ha sido tenido en cuenta el género como un factor en este proceso. Véanse los trabajos de Mónica Moreno Seco, entre los que cabe mencionar "Cristianas por el feminismo y la democracia. Catolicismo femenino y movilización en los años setenta", Historia Social, 53 (2005): 137-154; o "De la caridad al compromiso: las mujeres de Acción Católica (1958-1968)”, Historia Contemporánea, 26 (2003): 239-265. 
mundial ${ }^{7}$. Así, ante la incapacidad de la Iglesia para ofrecer una moral compatible con la vivencia moderna de la sexualidad, muchas personas católicas se vieron cada vez más legitimadas para ignorar ciertos preceptos religiosos, o incluso para abandonar la fe. Por tanto, las enseñanzas de la Iglesia en materia de sexualidad comenzaron a ser fuertemente cuestionadas y, con ello, la autoridad moral católica en general. La decepción que provocó la publicación de la Humanae vitae y la negativa del Vaticano a admitir la píldora como un anticonceptivo lícito tuvo enormes repercusiones en este sentido. Como señala David Geiringer en un reciente estudio, en la medida en que muchas personas sintieron que la Iglesia se equivocaba en esta decisión, se preguntaron si también podía estar errada en otros de sus juicios y políticas ${ }^{8}$. De ese modo, la institución eclesiástica pierde fuerza moral, a la vez que se extiende una vivencia más personal de la religión y una concepción menos jerárquica y más democrática de la misma, fruto asimismo de los cambios derivados del Vaticano II.

En definitiva, la cuestión sexual resulta interesante para estudiar los cambios en la moral religiosa, lo que también es sugerente en el contexto de la crisis del nacionalcatolicismo. No hay que olvidar que el régimen franquista había instaurado una moral sexual católica particularmente reaccionaria como un aspecto clave de su proyecto político. Los valores de castidad y jerarquía eran elementos relevantes del discurso político franquista, ideales que ahora se quiebran como consecuencia de los cambios culturales de la época ${ }^{9}$. Además, una parte de la comunidad católica se va a distanciar de una concepción autoritaria de la religión. Asimismo, no hay que olvidar que estos cambios tenían lugar en el contexto de la relativa liberalización cultural que siguió a la Ley de Prensa de 1966, así como en el de la emergencia de un sector de intelectuales y de una prensa crítica con el régimen ${ }^{10}$. En este sentido, cabe destacar revistas como El Ciervo, Triunfo o Cuadernos para el Diálogo. En este artículo

\footnotetext{
${ }^{7}$ David Geiringer, The Pope and the Pill...

${ }^{8}$ Ibidem.

${ }^{9}$ Aurora Morcillo, En cuerpo y alma. Ser mujer en tiempos de Franco (Madrid: Siglo XXI, 2015); Mónica García Fernández, “'Dos en una sola carne'. Matrimonio, amor y sexualidad en el franquismo (1939-1975)" (Tesis doctoral, Universidad de Oviedo, 2019).

${ }^{10}$ Francisco Rojas Claros, "Poder, disidencia editorial y cambio cultural en la España de los años sesenta", Pasado y Memoria, 5 (2006): 59-80; Javier Muñoz Soro, "Intelectuales, revistas y editoriales en la crisis del franquismo: el caso de Cuadernos para el Diálogo y Edicusa (1963-1975)", Trocadero, 18 (2006): 23-44; Juan Francisco Fuentes, "Prensa y política en el tardofranquismo (1962-1975). La rebelión de las élites", Cercles, 6 (2003): 12-32; Feliciano Montero, "Intelectuales católicos, del colaboracionismo al antifranquismo", Historia del Presente, 5 (2005): 41-68.
} 
examinaré estas y otras publicaciones, incluyendo también prensa femenina ${ }^{11}$. Del mismo modo, recurriré a algunas evidencias provenientes de fuentes orales, las cuales nos permiten apreciar la recepción de estos debates por parte de las mujeres, así como algunas de sus respuestas y estrategias ante el rechazo de la Iglesia a los anticonceptivos $^{12}$.

\section{LA SEXUALIDAD EN EL CONCILIO VATICANO II}

[...] aqui en el pueblo, hubo una mujer que tuvo hasta veintidós hijos. Yo me imagino que no querría tener veintidós hijos. Habia familias de diez y doce, y se veía claramente que, cuando llegaban a tener un montón de hijos, el matrimonio empezaba a no funcionar bien porque se ve que el método que usaban era el de no acercarse el uno al otro, y eso en un matrimonio es nefasto. Un matrimonio necesita la relación sexual como... como es normal, ¿no? Pienso yo que... que eso es... es humano y es... está dentro de lo... de lo natural. Cuando una pareja no puede tener unas relaciones [...] sexuales intimas, se va a deteriorar, se puede deteriorar. La sexualidad, dentro de la pareja y del matrimonio, creo que es importantísimo. Los matrimonios empezaron a sentir algo cuando el Concilio habló de una paternidad responsable [...]. Entonces los... los anticonceptivos vinieron a... a dar una revolución muy grande porque [...] las parejas pudieron adaptar su vida a la cantidad de hijos que querían tener o que podían tener ${ }^{13}$.

Este testimonio muestra la experiencia de una mujer católica nacida en 1940, madre de cinco hijos e implicada en Acción Católica. Sus reflexiones vienen a sintetizar algunas de las inquietudes que tuvieron lugar en el contexto del Vaticano II en torno al amor y la sexualidad. Dentro de un sector del catolicismo va a ser evidente una revalorización de las relaciones sexuales como un elemento imprescindible para la cohesión de la pareja. Ello implicaba la convicción de que, sin una expresión satisfactoria del amor sexual en el matrimonio, este se resentiría. Como afirmaba un

\footnotetext{
${ }^{11}$ Además de otros ensayos y publicaciones sobre el tema, las principales revistas analizadas son Triunfo, El Ciervo, Cuadernos para el Diálogo, Iglesia Viva, Proyección, Ecclesia, Cromosoma X, Índice, Senda, Teresa, Telva, Mundo Cristiano y Diario Femenino.

${ }^{12}$ Las fuentes orales proceden del Archivo audiovisual: Madres e hijas de la Transición española, https://mujerymemoria.org

${ }^{13}$ Ibídem. Mujer nacida en 1940. Cód. JGR-27 [Cinta 35].
} 
MónICA García Fernández

Sexualidad y religión en el tardofranquismo. La recepción de la Humanae Vitae en España y la crisis de autoridad de la Iglesia

moralista de la época, "si los esposos no tienen relaciones carnales, es porque falta algo a su amor"14.

Esto mismo sugiere el relato con el que inicié este apartado. Para esta mujer, un número excesivo de hijos desencadenaba un alejamiento sexual de la pareja $\mathrm{y}$, como consecuencia, un deterioro del amor conyugal. Esta es una opinión que confirmaban los estudios sociológicos de la época. A partir de una muestra de entrevistas realizadas con amas de casa, el informe FOESSA de 1969 evidenciaba que el número de hijos era la principal fuente de tensiones entre los cónyuges y también que el malestar psicológico de las mujeres se incrementaba a medida que aumentaba el tamaño de la familia ${ }^{15}$. La historia oral también nos acerca a esta realidad. Entrevistas realizadas por Eider de Dios o Agata Ignaciuk y Alba Villén documentan el cansancio que las cargas familiares y la doble jornada imponían sobre las mujeres, lo que se unía al miedo a los embarazos muy frecuentes ${ }^{16}$. Tal y como muestran estos testimonios, ello llevaba a las mujeres a rechazar y resentir las relaciones sexuales.

Los embarazos no deseados y la falta de disponibilidad de medios fiables de control de la natalidad eran, por tanto, una fuente de angustia para las mujeres, por más que hubiera quienes continuaron glorificando las alegrías que traía una prole abundante. Sin embargo, lo cierto es que, lejos de ser la norma, las familias numerosas eran la excepción, lo que no deja de ser paradójico a la luz de la exaltación que se hizo de ellas. A pesar de que las actitudes sobre el uso de anticonceptivos eran mayormente conservadoras, las tasas de natalidad mantuvieron una tendencia a disminuir, lo que muestra que, a pesar de las prohibiciones, la propaganda y los obstáculos, la población no había dejado de controlar el tamaño de sus familias. Además, las indagaciones sociológicas indican que "la parejita" se estaba consolidando como el ideal, especialmente entre las clases medias. Los informes FOESSA muestran como las

\footnotetext{
${ }^{14}$ Jacques Leclercq, ¿Matrimonio de amor, hoy? (Bilbao: Desclée de Brouwer, 1968), 135.

15 Fundación FOESSA, Informe sociológico sobre la situación social en España 1969 (Madrid: Euramérica, 1970), 616-620.

${ }^{16}$ Eider de Dios Fernández, "Domesticidad y familia: Ambigüedad y contradicción en los modelos de feminidad en el franquismo", Feminismo/s, 23 (2014): 23-46, doi: http://dx.doi.org/10.14198/fem.2014.23.02; Agata Ignaciuk y Alba Villén Jiménez, “¿Una pequeña revolución sexual? Experiencias de sexualidad y anticoncepción de mujeres andaluzas entre los años cincuenta y ochenta del siglo XX", Dynamis, 38 (2018): 303-331, doi: https://dx.doi.org/10.4321/S021195362018000200002
} 
expectativas y opiniones sobre lo que se consideraba un número idóneo de hijos tendían a disminuir ${ }^{17}$.

De hecho, incluso el discurso católico fue aceptando la necesidad de una cierta regulación de la natalidad. Si bien se insistía en que los matrimonios debían aceptar generosamente todos los hijos que pudieran, se admitía que era conveniente una cierta planificación en función de las posibilidades de cada pareja. El objetivo era impedir que las cargas de una prole excesiva tuvieran efectos negativos sobre la salud de la madre o la educación del resto de los hijos. De ese modo, se defendió la posibilidad de planear de forma más racional el tamaño de la familia y de espaciar los embarazos para dejar descansar el cuerpo materno. Así, los católicos empezaron a hablar de "paternidad responsable", un concepto que se consolidó especialmente con el Concilio Vaticano II. Fue la Gaudium et spes (1965) la que definió con mayor precisión esta idea, afirmando que, si bien el matrimonio estaba ordenado a la procreación, no debía ser un simple instrumento de esta. La constitución pastoral reconocía que el matrimonio debía cumplir con la norma de dar hijos, pero que esta debía basarse en un juicio consciente por parte de los cónyuges ${ }^{18}$. Sin embargo, la Gaudium et spes no resolvía el problema de los medios de control de la natalidad que podían utilizarse para practicar la paternidad responsable, ya que no abordaba la cuestión de la píldora, que en aquel momento era objeto de un intenso debate. A la espera de que se dictaminara un juicio definitivo sobre los anovulatorios, la constitución pastoral se remitía al magisterio vigente, que solo admitía el método Ogino como lícito.

La admisión de la paternidad responsable venía además acompañada de un cambio significativo en la concepción católica del amor conyugal. La Gaudium et spes va a prescindir de la llamada "jerarquía de los fines" que tanto se repetía en la época y que insistía en que el amor era un fin secundario del matrimonio, subordinado al de la

\footnotetext{
${ }^{17}$ Salustiano del Campo y María del Mar Rodríguez-Brioso, "La gran transformación de la familia española durante la segunda mitad del siglo XX", Reis, 100 (2002): 103-165; Juan Díez Nicolás, "Status socioeconómico, religión y tamaño ideal de la familia urbana", Revista Española de la Opinión Pública, 2 (1965): 83-108; Fundación FOESSA, Informe sociológico sobre la situación social en España 1969, 474482 y Estudios sociológicos sobre la situación social de España 1975 (Madrid: Euramérica, 1976), 345366; Jesús M. de Miguel, "Sociología de la población y control de la natalidad en España", Reis, 10 (1980): 15-47.

${ }^{18}$ Narciso Tibau, "Paternidad responsable. Expresión nueva en el magisterio de la Iglesia”, Ecclesia, 26 de marzo de 1966; Pablo VI, Constitución pastoral Gaudium et spes sobre la Iglesia en el mundo actual, 7 de diciembre de 1965, http://www.vatican.va/archive/hist_councils/ii_vatican_council/documents/vatii_const_19651207_gaudium-et-spes_sp.html
} 
procreación $^{19}$. En cambio, la constitución pastoral va a reconocer el amor y la procreación como objetivos inseparables del enlace, sin que ninguno estuviera subordinado al otro. De ese modo, el discurso conciliar optaba por acentuar la dimensión afectiva de la sexualidad y concedía relevancia a la intimidad sexual dentro del matrimonio como expresión y promoción del amor conyugal, lo que suponía una novedad en un escrito emanado de la Santa Sede. Hasta entonces, como señalaba un autor de la época, las relaciones sexuales podían estar, a lo sumo, legitimadas dentro del matrimonio, pero "nunca se había afirmado en documentos magisteriales que la intimidad sexual, en sí misma, objetivamente, en su misma estructura, expresara y fomentara el amor conyugal" 20 .

En definitiva, en contraposición al énfasis puesto hasta entonces en el mandato de perpetuar la especie, la teología posconciliar va a criticar una concepción del matrimonio como un instrumento de la procreación. En cambio, se insistía ahora en que el amor de los esposos no debía ser entendido como un valor secundario. La importancia de esta transformación para las personas católicas la expresaba de nuevo la mujer con cuyo testimonio inicié este apartado. Esto "sí que fue una revolución para nosotros asegura- $-[\ldots]$. Ya no era el matrimonio que te casabas para criar hijos para el cielo. Ya era un matrimonio que te casabas para la realización personal [...] de los cónyuges. Para ser felices y para poder, claro, $[\ldots]$ también ser fecundos. Pero $[\ldots]$ no solo fecundos en tener hijos" $" 21$.

\section{EL DEBATE SOBRE LA PÍLDORA}

Estos cambios abrieron un debate sobre los medios que podían utilizarse para lograr esta paternidad responsable, de modo que la procreación no fuera en detrimento de la concepción de la relación sexual como un instrumento de perfeccionamiento del amor de los esposos. Además, esta disputa coincidió con la difusión de la píldora, que se

\footnotetext{
19 Pío XI, Carta encíclica Casti connubii sobre el matrimonio cristiano, 31 de diciembre de 1930, https://w2.vatican.va/content/pius-xi/es/encyclicals/documents/hf_p-xi_enc_19301231_casticonnubii.html

20 José Martínez de Lahidalga, "Exigencias de la castidad conyugal, en sus aplicaciones pastorales, despuntes de la Humanae vitae", Iglesia Viva, 19-20 (1969): 46.

${ }^{21}$ Mujer nacida en 1940. Entrevista realizada para el Archivo audiovisual: Mujer y memoria. Madres e hijas de la Transición española. Cód. JGR-27 [Cinta 35], https://mujerymemoria.org
} 
estaba popularizando como un remedio eficaz para el control de la natalidad. En este contexto, algunos católicos empezaron a defender este método como lícito en algunos supuestos y a plantearse la legitimidad de los anticonceptivos, poniendo en cuestión un mandato hasta entonces tremendamente arraigado en la teología católica.

Hay que tener en cuenta que, si bien la Gaudium et spes defendía la paternidad responsable y evitaba el lenguaje de la jerarquía de los fines, el matrimonio seguía considerándose como igualmente destinado a la procreación. Además, la paternidad responsable debía ejercerse a través de la continencia periódica y la constitución pastoral era tajante a la hora de recordar que no era lícito utilizar aquellos métodos prohibidos por la Iglesia. Sin embargo, en el Vaticano II se evitó tomar una decisión sobre la píldora. Con todo, sí se reconoció la necesidad de revisar la doctrina, teniendo en cuenta que había quienes abogaban por la conveniencia de una mayor laxitud sobre los anticonceptivos. Por ello, Juan XXIII había formado en 1963 una comisión para el estudio de la población, la familia y los problemas de natalidad. En ella participaban distintos especialistas, teólogos, científicos y grupos de matrimonios. Tras la muerte del pontífice ese mismo año, Pablo VI amplió la comisión y se reservó una opinión definitiva sobre el tema, que no llegaría hasta 1968. Para evitar crear confusión y diversidad de pareceres sobre este tema de crucial importancia, el papa rogó a la comunidad católica que se atuviera a las normas vigentes y que se cuidara de no difundir opiniones contrarias a las mismas hasta que no se hubiera tomado una decisión concluyente. Sin embargo, lo contrario fue precisamente lo que ocurrió.

En el contexto de los debates sobre el control de la natalidad se fue apreciando una pugna entre quienes eran partidarios de una revisión de las políticas de la Iglesia sobre la sexualidad, frente a otro sector más conservador que rechazaba abandonar la idea de que el fin primario del matrimonio era la procreación ${ }^{22}$. Esta división se agudizó con la incorporación de la problemática de la píldora, que venía a introducir la posibilidad de separar los factores afectivos y procreativos de la expresión sexual del matrimonio, sin recurrir a los métodos de control de la natalidad tradicionalmente condenados por la Iglesia. Por ello, algunos miembros reconocidos de la jerarquía eclesiástica comenzaron a plantearse la posibilidad de reconocer el uso del novedoso fármaco para practicar la paternidad responsable, a la vez que se salvaguardaba el amor

\footnotetext{
${ }^{22}$ Susan Rakoczy, “A Gendered Critique of the Catholic Church's Teaching on Marriage and the Family: 1965-2016”, Scriptura, 116 (2016): 1-19.
} 
mutuo, cuando la continencia periódica fuera origen de tensiones o fuera en detrimento de los aspectos emocionales de la unión.

Así, algunos sectores más progresistas se mostraron esperanzados por las expectativas de una apertura en la doctrina católica, pero tampoco faltaron quienes se opusieron a cualquier cambio. En nuestro país, este fue el caso de autores como Antonio Peinador Navarro o también Marcelino Zalba, quien además era miembro de la comisión pontificia formada para asistir al papa en su decisión. Para estos, ninguna indicación, por grave que fuese, podía justificar un acto que frustrase el poder de engendrar vida, lo que consideraban una ofensa contra la naturaleza y un grave pecado. Estos moralistas recordaban que la Iglesia siempre se había opuesto al control de la natalidad y que debía seguir haciéndolo. Peinador Navarro, por ejemplo, criticaba las palabras indulgentes de quienes eran partidarios de un cambio, por poner en peligro lo que se suponían las virtudes de la castidad y la necesaria mortificación del instinto ${ }^{23}$.

Si bien la postura oficial de la Iglesia fue la de rechazar la píldora como medio anticonceptivo, su uso va a ir aceptándose como lícito en aquellos supuestos que tenían que ver con indicaciones terapéuticas, para regular la menstruación o favorecer el descanso del útero durante la lactancia ${ }^{24}$. Así es como se comercializó en España a partir de 1964, como un fármaco indicado para usos terapéuticos. Sin embargo, a pesar de que la venta y publicidad de anticonceptivos estuvo prohibida hasta 1978, ello no impidió que la píldora se popularizara, generándose además un intenso debate. Además, sus ventas también se multiplicaron, aunque se mantuvieron por debajo de la media europea $^{25}$. Junto con los moralistas, clérigos y teólogos católicos, los médicos fueron unos interlocutores clave en el debate sobre la píldora, teniendo en cuenta que eran los encargados de recetarla. Dado el posicionamiento religioso de buena parte de la clase médica en nuestro país, no es de extrañar que acudieran a argumentaciones morales y fueran mayormente conservadores en sus actitudes con respecto al control de la natalidad. Sin embargo, como ha estudiado Agata Ignaciuk, también hubo quienes

\footnotetext{
${ }^{23}$ Antonio Peinador Navarro, Los hijos ¿para qué? Razones y dificultades para una procreación regulada (Madrid: Coculsa, 1968).

24 José López Navarro, Matrimonio, natalidad, píldora (Madrid: Palabra, 1967); Juan Ramón López Arévalo, Un problema matrimonial ¿cuándo es lícita la píldora? (Madrid: Studium, 1967); Juan García Vicente y Bernard Häring, Regulación de nacimientos. Un problema familiar visto por un médico y un teólogo (Madrid: Editorial El Perpetuo Socorro, 1965); Lorenzo Gomis, "Píldora y natalidad", El Ciervo, agosto-septiembre de 1964, 11; Antonio Peinador Navarro, Los hijos ¿para qué?...
}

${ }^{25}$ Agata Ignaciuk y Teresa Ortiz Gómez, Anticoncepción, mujeres y género... 
MónICA GaRCÍA FERNÁNDEZ

Sexualidad y religión en el tardofranquismo. La recepción de la Humanae Vitae en España y la crisis de autoridad de la Iglesia

empezaron a defender la independencia de la práctica clínica de los criterios teológicos y a mostrarse partidarios de fomentar una planificación familiar, algo que se hizo cada vez más evidente a medida que se acercaba el ocaso del régimen franquista ${ }^{26}$.

El debate médico se orientó además en torno a la definición de lo que suponía una indicación terapéutica. Como señala Ignaciuk, este criterio fue en ocasiones lo suficientemente ambiguo y flexible como para incluir circunstancias diversas, que podían ser no solo las físiológicas, como dismenorrea, reposo del útero durante la lactancia, peligro grave para la salud o la vida de la madre; sino también las sociales, como evitar un embarazo no deseado en una familia sin recursos; o los psicológicos, como el miedo patológico a un embarazo. Los límites de lo que se entendía como una necesidad social o psicológica podían variar en función del talante del profesional y su visión más o menos favorable a la planificación familiar. Así, los más reaccionarios se opusieron a la píldora y la consideraron como un medio equivalente al aborto, como un instrumento que masculinizaba a la mujer o como un peligro para el ideal de familia cristiano. Otros, en cambio, empezaron a hablar de la anticoncepción como un derecho y a implicarse en la creación de consultas de planificación familiar a finales de la dictadura y durante la transición a la democracia ${ }^{27}$.

Además del debate médico y teológico, se publicaron en nuestro país toda clase de libros, folletos y artículos sobre el tema ${ }^{28}$. La píldora también llegó a las revistas femeninas pero, como señala Ignaciuk, estas difundieron una opinión mayormente negativa sobre el control de la natalidad. Sin embargo, incluso con juicios contrarios al fármaco, no dejaron de contribuir a su popularización y difusión entre el público general $^{29}$. En realidad, a pesar de que la Gaudium et spes alababa a las familias numerosas, el reconocimiento de la paternidad responsable no dejó de causar resquemores entre quienes pensaron que se trataba de una crítica a quienes, fieles al magisterio de la Iglesia, habían aceptado sin reservas todos los hijos que Dios les había

\footnotetext{
${ }^{26}$ Ibídem; ; Esteban Rodríguez-Ocaña, Agata Ignaciuk y Teresa Ortiz, "Ovulostáticos y anticonceptivos: El conocimiento médico sobre 'la píldora' en España durante el franquismo y la transición democrática (1940-1979)", Dynamis, 32, 2 (2012): 467-494, doi: http://dx.doi.org/10.4321/S021195362012000200009; Salustiano del Campo, "Los médicos ante el problema de la limitación de la natalidad”, Revista Española de la Opinión Pública, 1 (1965): 27-38.

27 Teresa Ortiz-Gómez y Agata Ignaciuk, "The Fight for Family Planning in Spain during Late Francoism and the Transition to Democracy, 1965-1979”, Journal of Women's History, 30, 2 (2018): 38-62, doi: https://doi.org/10.1353/jowh.2018.0013

${ }^{28}$ Agata Ignaciuk y Teresa Ortiz, Anticoncepción, mujeres y género...

${ }^{29}$ Ibídem.
} 
MónICA GaRCÍA FERNÁNDEZ

Sexualidad y religión en el tardofranquismo. La recepción de la Humanae Vitae en España y la crisis de autoridad de la Iglesia

enviado. Esto era lo que planteaba una lectora de Mundo Cristiano, que interpretaba las ideas favorables a tener un número razonable de hijos como un ataque a la incontinencia de los padres de familias numerosas. Hacía igualmente referencia al concepto de sacrificio cristiano, que implicaba un rechazo de la "vida fácil".

[...] el tener muchos hijos lo mismo puede ser signo de muy católicos que de instintos animalescos. ;Habrase visto! Los que no los tienen son lo verdaderamente incontinentes y los que hablan vergonzosamente de los mil medios de no tener hijos; los que son generosos y tienen hijos están ya capacitados para dar otros sacrificios como son la continencia en tiempos de penitencia. [...] Parece que queremos excluir todo lo que nos molesta, queremos una religión fácil, sin cruz. ¿En qué nos vamos a diferenciar los matrimonios católicos de los demás? En nada; ya llevamos el mismo cálculo repugnante de los poquitos hijos y del vivir bien ${ }^{30}$.

No hay que olvidar que Josemaría Escrivá de Balaguer había alzado su voz en rechazo de cualquier renovación en materia de control de la natalidad. Así lo mostró en varias entrevistas publicadas en Telva y Mundo Cristiano, ambas afines al Opus Dei. "Son criminales, anticristianas e infrahumanas las teorías que hacen de la limitación de los nacimientos un ideal o un deber [...]. Sería adulterar y pervertir la doctrina cristiana querer apoyarse en un pretendido espíritu postconciliar para ir contra la familia numerosa", afirmaba ${ }^{31}$.

Algo diferente era, en cambio, la actitud de la revista de mujeres de Acción Católica, Senda, que en 1965 realizaba un sondeo que revelaba una espíritu más abierto y dispuesto a conocer la opinión del público general y a dar voz a las mujeres y no solo a los sacerdotes, médicos y teólogos que habitualmente aparecían en la prensa. Las que mostraron su interés en la encuesta y enviaron sus respuestas a la revista fueron sobre todo madres de familia numerosa, con más de cuatro hijos de media e incluso con siete, ocho y nueve hijos. Ello suponía una fuente de legitimación para la publicación, que afirmaba que las opiniones no provenían de mujeres egoístas que "buscaban el camino cómodo" y que solo querían eludir sus responsabilidades ${ }^{32}$.

\footnotetext{
${ }^{30}$ Mundo Cristiano, junio de 1965.

31 “Una entrevista con Mons. Josemaría Escrivá de Balaguer”, Mundo Cristiano, marzo de 1968. Sobre el carácter conservador del Opus Dei en materia de género y sexualidad, véanse Mónica Moreno Seco, "Mujeres de Acción Católica y el Opus Dei. Identidades de género y culturas políticas en el catolicismo de los años sesenta", Historia y Política, 28 (2012): 167-194; o Sofía Rodríguez López, "Las mujeres del Opus Dei (1930-1980): Género, clase y fe", Hispania Nova, 18 (2020): 551-598.

${ }^{32}$ Senda, números de enero a mayo de 1965.
} 
Para el 91,37 por 100 de las encuestadas, el control de la natalidad era un problema grave y urgente. También la gran mayoría, un 93,5 por 100, opinaba que la regulación estaba justificada en algunos casos excepcionales, mientras que el 60,55 por 100 consideraba que casi siempre había motivos razonables para ello. Algo más dividida estaba la opinión sobre la utilidad de los métodos aceptados por la Iglesia, pero eran más de la mitad, un 51,55 por 100, las que juzgaban que los medios autorizados no resolvían el aprieto. Por lo general, las mujeres cuyo sentir se veía reflejado en la encuesta se reconocían partidarias de las familias numerosas, pero reclamaban mejores posibilidades para espaciar los nacimientos y una mayor racionalidad a la hora de tener hijos, con el fin de no perjudicar su educación ni la salud de la madre. Uno de los testimonios señalaba también las dificultades que una prole numerosa traía para la vida sexual del matrimonio y las consecuencias negativas para la expresión afectiva de la pareja.

[...] a los dieciséis años de matrimonio decidió no tener relaciones intimas porque decía me quería mucho y no deseaba exponerme a tener más hijos, cosa que ya no queríamos. Mi marido es un hombre honrado, bueno y correcto, pero no se pueden figurar lo que es para una mujer vivir al lado de un hombre que quiere casi como un extraño ${ }^{33}$.

Junto con los dictámenes conservadores que encontramos en revistas como Telva o Mundo Cristiano, también se difundieron juicios más favorables o matizados que al menos contemplaban la posibilidad de entablar un debate y un diálogo entre distintas corrientes. Estas tendían a poner el énfasis en la paternidad responsable, en la importancia de la sexualidad para fomentar el amor conyugal y en la libertad de la persona cristiana para tomar decisiones de forma responsable. Este tipo de ideas las podemos leer en revistas como El Ciervo, Triunfo o Cuadernos para el Diálogo. Si bien estas procuraban no ir en contra del magisterio de la Iglesia en un momento en el que aún no se había tomado una decisión definitiva, sí es posible inferir de estas publicaciones un talante abierto a la renovación de las enseñanzas tradicionales.

En la revista fundada por Joaquín Ruiz Giménez aparecieron varios artículos que planteaban que la píldora, al igual que la abstinencia periódica, era un método natural y que, por tanto, no podía equipararse a aquellos tradicionalmente rechazados por la Iglesia. Este juicio se explica por el hecho de que el fármaco no interrumpía el desarrollo de la relación sexual, como supuestamente lo hacían los preservativos o el

\footnotetext{
${ }^{33}$ Senda, abril de 1965.
} 
coitus interruptus, sino que venía simplemente a inducir una función natural del cuerpo femenino, al reproducir los ciclos normales del organismo ${ }^{34}$.

Además, las opiniones que se difundieron en Cuadernos para el Diálogo pueden entenderse en el contexto de emergencia de un feminismo católico ${ }^{35}$. En 1964 escribía sobre el tema Lilí Álvarez, quien llamaba la atención sobre la importancia que tenían para los derechos de las mujeres los cambios en el significado del matrimonio que se estaban produciendo en los debates y documentos conciliares. En su opinión, la jerarquía de los fines del matrimonio convertía a la mujer en un instrumento para la procreación. Según explicaba, ello provenía de una concepción aristotélico-tomista que consideraba a la mujer como un varón malogrado, un ser inferior cuya función era la de ser vasija en la que depositar la semilla masculina. Igualmente, la autora exaltaba la paternidad responsable y defendía que la procreación debía ser una decisión razonable, en función de las circunstancias, así como fruto de un acuerdo entre los cónyuges, partiendo de una igualdad y respeto mutuos. "Ya ha pasado la hora de la llamada 'procreación espontánea', del simple e instintivo tener 'todos los hijos que Dios envía' (¡menudo papel le hacen hacer a Dios!)”, afirmaba ${ }^{36}$. Para Lilí Álvarez, traer hijos al mundo no suponía el mero hecho de concebirlos y parirlos, función que hacían también los animales, sino sobre todo la misión de educarlos. De ese modo, hacía hincapié en los valores humanos frente a la "ley natural" en la que insistían los sectores inmovilistas.

En otro artículo de Cuadernos para el Diálogo, el Dr. Peláez Redondo urgía al Vaticano a tomar una decisión que se adaptase a la conducta sexual de la población. E1 médico se refería a las tensiones y desórdenes que el problema del control de la natalidad producía en las parejas. Según afirmaba, estas "llevan una vida sexual irregular, llena de sobresaltos, temores y escrúpulos para impedir un nuevo embarazo". A su juicio, el resultado era que los católicos más dóciles a las rígidas normas católicas podían caer en estados de angustia y ansiedad, mientras que al resto no le quedaría más

\footnotetext{
${ }^{34}$ J. Peláez Redondo, "El control de la natalidad: testimonio de un médico", Cuadernos para el Diálogo, diciembre de 1966.

35 Mónica Moreno Seco, “Cristianas por el feminismo y la democracia...”; "De la caridad al compromiso..."

${ }^{36}$ Lilí Álvarez, "El control de la natalidad", Cuadernos para el Diálogo, diciembre de 1964.
} 
remedio que ignorar o desentenderse de estas indicaciones, apartándose así de la Iglesia $^{37}$.

\section{¿AMOR O PROCREACIÓN?}

A lo largo de los años sesenta es apreciable un cambio sustancial en el discurso católico progresista, que pasa a definir la sexualidad como un "lenguaje del amor" ${ }^{\text {, }}$. De ese modo, la sexualidad pasa a ser entendida como una forma de comunicación del amor y se va a tender a poner especial énfasis en su valor afectivo, disminuyendo en cambio su importancia en la procreación. Como decía el Dr. Juan Vilaltella Gran, "la reproducción es un proceso totalmente marginal de la relación con el otro, puesto que la sexualidad en el fondo no es reproducción sino comunicación" ${ }^{39}$.

Algunos intelectuales católicos, teólogos y sacerdotes van a reflexionar sobre el papel de la sexualidad en el mundo moderno, haciendo hincapié en la unión entre sexualidad y afectos. Es el caso del padre escolapio y filósofo catalán Octavio Fullat. En 1966 publica La sexualidad: carne y amor, donde va a tratar de corregir la moral católica tradicional, criticando su tendencia a valorar el amor platónico como superior. En su lugar, define la sexualidad como una forma de comunicación a través del cuerpo y la presenta como un encuentro interpersonal, no solo como un medio para la procreación. Para Fullat, no era ni el mero placer, ni tampoco la procreación, sino la comunicación del afecto, lo que caracterizaba la sexualidad ${ }^{40}$. Además, si bien se trataba de un ensayo filosófico que se popularizó sobre todo entre estudiantes universitarios, estas ideas se reprodujeron y difundieron también a través de otros medios, como El libro de la vida sexual, que estuvo en la lista de los títulos más vendidos del país a finales de los años sesenta ${ }^{41}$.

\footnotetext{
${ }^{37}$ J. Peláez Redondo, "El control de la natalidad...".

38 A. López Caballero, “La sexualidad como lenguaje del amor”, Proyección, 56 (1967): 209-215.

39 Juan Vilaltella Gran, "El sentido de la sexualidad", Cromosoma X, 35 (1969): 29.

${ }^{40}$ Octavio Fullat, La sexualidad: carne y amor (Barcelona: Nova Terra, 1966).

${ }^{41}$ Juan José López Ibor, El libro de la vida sexual (Barcelona: Dánae, 1968); Mónica García Fernández, "Dos en una sola carne..."
} 
Este énfasis en la dimensión emocional de la sexualidad dejaba abierta una cuestión importante, la del control de la natalidad. Si efectivamente el amor, y no la procreación, era el fin de la sexualidad, ¿podía derivarse de ello la licitud de los anticonceptivos? Muchos admitían que el miedo al embarazo impedía la libre expresión del amor sexual en el matrimonio, lo que tendría repercusiones negativas sobre la relación personal entre los esposos. Lo normal en este caso era que los moralistas católicos solucionaran esta disyuntiva mediante la defensa de la abstinencia periódica. Sin embargo, la píldora ofrecía nuevas posibilidades, en la medida en que era segura y eliminaba el factor de tener que ceñirse a lo que se conocía como "amor de calendario". En su ya citado ensayo sobre la sexualidad, Octavio Fullat aludía a este tema y se mostraba partidario de la paternidad responsable, pero evitaba tomar partido sobre la píldora en un momento en el que la Santa Sede aún no había llegado a una decisión definitiva $^{42}$. No por ello dejaba de mostrar un talante abierto al diálogo y a la renovación que se contraponía de forma evidente al de otros sectores más inmovilistas ${ }^{43}$.

Así, además de afirmar que el famoso "creced y multiplicaos” del Génesis no era una orden, sino una bendición y que "el hijo es la consecuencia del acto sexual, pero no la finalidad", aseguraba que la reducción de la sexualidad a la procreación suponía su deshumanización ${ }^{44}$. Aunque de forma algo sutil y ambigua, el filósofo mostraba una actitud favorable a un cambio en la doctrina eclesiástica sobre el particular. Además, admitía el carácter histórico y cultural del problema, señalando que "no debemos contemplar la sexualidad humana como algo definitivo, adquirido de una vez para siempre, sino como una realidad evolutiva que constantemente ha de hacerse dentro de las coordenadas espaciotemporales" $" 45$.

Algo más explícito era este mismo autor en un artículo de la revista Índice, donde repetía los anteriores argumentos, a la vez que defendía de una forma más clara el control de la natalidad $^{46}$. Para Fullat, la fecundidad debía ser humana, razonable y voluntaria, de modo que todo nacimiento fuera fruto de la libertad y la reflexión en función de las necesidades y circunstancias familiares. "Aquello de 'hijos, cuantos más

\footnotetext{
42 Octavio Fullat, La sexualidad...

${ }^{43}$ Antonio Peinador Navarro, Los hijos ¿para qué?...

${ }^{44}$ Octavio Fullat, La sexualidad..., 223.

${ }^{45}$ Ibídem., 240.

${ }^{46}$ Octavio Fullat, "Excursión por el control de la natalidad”, Índice, 207 (1966).
} 
mejor' es un grito antihumanista, es equiparar la procreación humana a la animal", aseveraba $^{47}$. Igualmente, proponía una revisión de los conceptos de "natural" y "antinatural", tan recurridos en el discurso católico. Con ello, argumentaba en contra de aquellos que objetaban que el uso de anticonceptivos iba contra la naturaleza, al bloquear una función biológica. A este respecto, recordaba que los seres humanos se sirven constantemente de procedimientos "artificiales" para modificar la naturaleza y mejorar sus vidas, entre los que se encontrarían los numerosos adelantos de la medicina. El mismo criterio debía aplicarse, pues, a los anticonceptivos.

Me pregunto: unos dientes postizos o tomarse una aspirina... ¿es algo natural o antinatural?; una operación quirúrgica, ¿es natural o antinatural? La respuesta no puede venir dada únicamente teniendo presente el cuerpo humano, sino la totalidad del hombre y la colectividad de los hombres. ¿Qué diferencia hay entre tomarse un piramidón para aliviar el dolor de cabeza y tomarse unas píldoras de progesterona cuando ya no pueden tenerse más hijos razonablemente? ${ }^{48}$

Esta redefinición del concepto de "naturaleza" estaba entre los razonamientos que empezaron a utilizarse entre aquellos moralistas abiertos a una renovación de las enseñanzas de la Iglesia. Además, se criticaba también una óptica excesivamente biológica por parte de la doctrina tradicional, frente a una concepción más humanista. Se insistía así en que el acto conyugal difería de la sexualidad animal, en la medida en que no se trataba de un mero acto reproductivo, sino la expresión de una unión interpersonal.

No se puede comprender la sexualidad como algo meramente biológico o animal, porque se lesiona su carácter personal y humano. $\mathrm{Ni}$ se puede admitir una pura ordenación a la procreación, olvidándose del amor que perfecciona a los esposos [...].

Por eso, desde un punto de vista antropológico-cristiano, el sentido de la sexualidad no puede agotarse en la generación, sino que es, de una forma igualmente importante, pauta y módulo de amor. Esto significa que la comprensión moral de los fármacos inhibidores de la ovulación debe deducirse no sólo de la generación, sino de la totalidad del fin del matrimonio. Es preciso ver si en ese más amplio contexto se oponen realmente a la Naturaleza del acto conyugal. ¿No será legítimo su uso como inhibidores directos de la ovulación,

\footnotetext{
${ }^{47}$ Ibídem.

${ }^{48}$ Ibídem.
} 
cuando se hace en beneficio del amor conyugal y generador de los esposos? ${ }^{49}$

Otros señalaban que era el matrimonio en su conjunto el que estaba ordenado a la procreación y no cada acto sexual individual. Bastaría entonces con que el matrimonio globalmente considerado persiguiera el fin de formar una familia, pero no sería necesario que todas las relaciones sexuales estuviesen abiertas a esa posibilidad. Quienes defendían un cambio, igualmente hacían hincapié en la necesidad de eliminar de la moral católica todos aquellos elementos rigoristas de tradición tomista $\mathrm{y}$ agustiniana que consideraban el placer sexual como un mal menor tolerado exclusivamente en el contexto de la procreación. Estos pasaban a considerarse como añadidos posteriores y provenientes de sectas paganas, pero ajenos a la verdadera doctrina de las sagradas escrituras ${ }^{50}$. En general, se tiende por tanto a rebajar la importancia de la procreación dentro del orden jerárquico de funciones de la vida sexual. "La sexualidad puede también ser procreación", aseguraba un autor. "Estaría presente como horizonte, pero dejaría de ser destino", continuaba ${ }^{51}$.

Todas estas ideas alimentaban el repertorio de argumentos en favor de admitir el uso de la píldora. En cambio, el método Ogino se consideraba ineficaz y un incordio para las mujeres, que tendrían que estar siempre pendientes del calendario y de las temperaturas. Además, frente a quienes insistían en que se trataba del único medio natural, otros autores subrayan justamente su carácter antinatural, al no permitir la libre expresión del amor sexual. ${ }^{52}$ En ese sentido cabe mencionar un monográfico publicado por la revista Proyección en 1967, en el que se llamaba la atención sobre la existencia de una contradicción entre las exigencias de la fecundidad y las del amor en la doctrina reciente de la Iglesia. Si, como planteaba la Gaudium et spes, ambos eran fines inseparables del matrimonio, al menos había que considerar que las consecuencias de una relación sexual podían, en realidad, ser un obstáculo para la comunicación del afecto y, en definitiva, tener repercusiones negativas sobre la relación conyugal si de

\footnotetext{
49 Juan García Vicente y Bernard Häring, Regulación de nacimientos..., 29.

${ }^{50}$ Ibidem.; VVAA, "Matrimonio y concilio", Proyección, 56 (1967): 195-230.

51 Juan García Vicente y Bernard Häring, Regulación de nacimientos..., 18.

${ }^{52}$ Ibidem., 21-22.
} 
MóNICA GARCía FernándeZ

Sexualidad y religión en el tardofranquismo. La recepción de la Humanae Vitae en España y la crisis de autoridad de la Iglesia

ello se derivaba un miedo a un embarazo no deseado ${ }^{53}$. De ese modo, se defendía una paternidad responsable que no tuviera consecuencias negativas sobre esa comunicación del amor, es decir, que no implicase una interrupción de las relaciones sexuales en los momentos en los que no convenía un embarazo. Uno de los autores del monográfico, Luis Espina, criticaba el fatalismo y el carácter azaroso de la fecundidad y cuestionaba el discurso sobre el "heroísmo" de las madres y padres a la hora de asumir de forma resignada la voluntad divina. Por ello, también ponía en duda la utilidad del método Ogino, que no hacía sino limitar y restringir la espontaneidad y la libre expresión del amor. Insistía también en que era preciso rebajar la importancia dada a la integridad biológica del acto físico, algo en lo que hacían hincapié quienes se oponían a los llamados "medios artificiales" de control de la natalidad, por supuestamente alterar una función tal y como había sido creada en la naturaleza. En cambio, este autor afirmaba que era la persona humana en su conjunto, y no las características de un acto físiológico concreto, la que debía ser digna de consideración.

Esto [...] supone una limitación del amor por lo biológico y un dar más importancia a la integridad fisiológica de unas células o de un proceso orgánico que a la posibilidad de expresión amorosa de los esposos. Así, ni al amor se le da un continuo derecho a expresarse sexualmente, ni, en consecuencia, se afirma con plenitud el papel de la sexualidad como expresión del amor. Prácticamente, además, se corta la espontaneidad del diálogo amoroso de los cónyuges — con las tensiones y rupturas que esto puede llevar consigo ${ }^{54}$.

Defiende por ello lo que denomina un "uso libre del matrimonio", basado en asegurar la infecundidad del acto sexual mediante el uso de un anticonceptivo eficaz. Ello permitiría afirmar "el derecho del amor conyugal a expresarse sexualmente", al suprimir las tensiones que provenían de la inseguridad de la continencia periódica. Como consecuencia, "se construye una moralidad cuya norma es el amor, y no el calendario o lo natural-fisiológico" 55 .

El teólogo Enrique Miret Magdalena fue uno de los autores que también mostró una actitud prudente, pero abierta hacia el control de la natalidad. Sus opiniones fueron

\footnotetext{
53 VVAA, "Matrimonio y concilio", Proyección, 56 (1967): 195-230; E. López Azpiarte, "Doctrina conciliar sobre la regulación de los nacimientos", Proyección, 56 (1967): 224-230.

${ }^{54}$ Luis Espina, “¿Cuántos hijos debe tener un matrimonio cristiano? Paternidad responsable o dimensión familiar de la regulación de nacimientos”, Proyección, 56 (1967): 221.

${ }^{55}$ Ibídem.
} 
trasmitidas sobre todo a través de Triunfo ${ }^{56}$. En sus numerosos escritos para el semanario, Miret Magdalena hacía hincapié en la paternidad responsable y criticaba una concepción del matrimonio como "máquina de producir vástagos". Subrayaba asimismo la inseguridad del método Ogino, dada la gran cantidad de mujeres cuyo ciclo menstrual era irregular. El teólogo definía el matrimonio como "una comunidad de vida y amor" y valoraba los aspectos emocionales de la sexualidad. Como prueba, declaraba que "la psicología ha descubierto que la sexualidad no es una cosa puramente material, sino directamente relacionada con la emotividad"57. Así, aseguraba que la sexualidad no debía considerarse como algo meramente biológico. Con ello, matizaba la obstinación de los conservadores por subrayar la necesidad de respetar la "ley natural" y afirmaba que la modificación de la naturaleza mediante los adelantos de la ciencia y de la técnica era un acto plenamente humano. De hecho, recordaba que constantemente se altera lo natural sin que ello se considere un pecado, por ejemplo, al arreglarse el pelo, cortarse las uñas o extraer un apéndice infectado ${ }^{58}$. Asimismo, rechazaba la actitud autoritaria de las jerarquías. En cambio, argumentaba en favor de reconocer la capacidad de los seglares para reflexionar de forma autónoma y de tomar decisiones en función de su conciencia $^{59}$.

\section{EL "INFORME DE LA MAYORÍA"}

Todas estas ideas se estaban difundiendo con anterioridad a que Pablo VI diera a conocer sus propias conclusiones definitivas. La comisión que se había constituido para asistirle elaboró un informe que fue entregado al sumo pontífice en 1966 y en el que se recomendaba a favor de una renovación del magisterio de la Iglesia. El documento hacía hincapié en la necesidad de adaptarse a un contexto en el que se había producido una importante transformación en la experiencia del matrimonio y de la intimidad familiar.

\footnotetext{
${ }^{56}$ Enrique Miret Magdalena, "Matrimonio y natalidad", Triunfo, 15 de febrero de 1975; "Paternidad responsable", Triunfo, 24 de febrero de 1968; "Píldora sí, píldora no", Triunfo, 17 de febrero de 1968; “¿Otra vez la píldora?”, Triunfo, 14 de marzo de 1972; "La Iglesia y la natalidad”, Triunfo, 11 de julio de 1964.

${ }^{57}$ Enrique Miret Magdalena, Los nuevos católicos (Barcelona: Nova Terra, 1966), 389.

${ }^{58}$ Ibidem., 391.

${ }^{59}$ Ibidem., 172, 236-237.
} 
De ese modo, se admitía el carácter cultural y variable de la sexualidad, lo que suponía una novedad en el discurso católico. Tal y como reconocía el informe, la promoción de la mujer, la reducción de la mortalidad infantil, los nuevos conocimientos de la biología, la psicología y la sexología habían dejado una gran impronta que debía ser reconocida también por la jerarquía eclesiástica. Igualmente, el documento llamaba la atención sobre la inseguridad de los métodos tradicionales para evitar la concepción, que además condenaban a los esposos a largos periodos de abstinencia que resultaban perjudiciales para la unión conyugal. Se manifestaba asimismo un temor a que se produjera un alejamiento de la religión por parte de la comunidad de fieles en caso de que se optase por un inmovilismo ${ }^{60}$.

Ello no quiere decir que se suprimiese la idea de que el matrimonio estaba ordenado a la procreación, pero se convenía que este mandato no obligaba a cada acto sexual individual, sino a todo el matrimonio entendido en su conjunto. Además, el documento redefinía lo que se entendía por un matrimonio fecundo, que debía afectar a una realidad más amplia que incluyera la creación de un ambiente en el que pudiera florecer el amor y que permitiera educar a los hijos en las mejores condiciones. De ahí que las relaciones sexuales estériles también se considerasen fértiles en la medida en que servían para nutrir esa unión afectiva. Esta creativa utilización y reinterpretación del mandato de la procreación permitía defender un cambio en la doctrina que siempre se había considerado inmutable a la vez que se mantenía una continuidad con la moral tradicional, insistente en la idea de que el fin del matrimonio era la fecundidad.

La "comunidad procreadora responsable" siempre se orienta a la procreación; éste es el sentido objetivo y auténtico de la sexualidad $y$ de todo aquello que se refiere a la sexualidad (afectividad, unidad, capacidad de educación, etc.). De ahi que podamos hablar del fin procreador como el fin esencial de la sexualidad y de la vida conyugal.

Pero este fin procreador no debe ser realizado por el acto fecundo, cuando, por ejemplo, los padres ya tienen hijos que educar o no están preparados para engendrar un hijo. Esta obligación de conciencia de no procrear proviene de los derechos naturales que tiene el hijo presente o que deberá tener el futuro; el hijo tiene derecho a la "comunidad de amor y de unidad" para poder ser educado y formado.

Por tanto, se mantiene en sustancia $y$ en verdad el fin procreador incluso cuando se excluye hic et nunc la fecundidad del

\footnotetext{
${ }^{60}$ Alfonso C. Comín, ed., Control y regulación de nacimientos. El “dossier” de Roma (Barcelona: Nova Terra, 1967).
} 
acto: porque la infecundidad va ordenada a posibilitar una nueva vida en condiciones adecuadas y humanas ${ }^{61}$.

Este documento fue aprobado por la práctica totalidad de los miembros de la comisión, algo más de sesenta. Sin embargo, cuatro integrantes disconformes, entre los que se encontraba el jesuita español Marcelino Zalba, firmaron otro texto inmovilista que hicieron llegar a Pablo VI. Este refutaba los argumentos de la mayoría y llamaba la atención sobre el egoísmo que suponía la búsqueda de placer sin consecuencias. Negaba también la noción de que las relaciones sexuales fueran imprescindibles para nutrir la relación entre los cónyuges. Para sus autores, el amor conyugal era principalmente espiritual, de modo que "no requiere expresión alguna carnal determinada y menos aún la repetición de la misma con una determinada frecuencia" ${ }^{\natural 2}$. Les preocupaba, además, que la credibilidad de la Iglesia se viera puesta en entredicho al revisar unas enseñanzas que hasta entonces se habían planteado como una normativa grave y definitiva. Ello implicaba reconocer que la Iglesia se había equivocado, lo que podía dar a entender que el magisterio del Vaticano no era infalible y se trataba solo de una mera opinión que podía someterse al escrutinio de la opinión pública y al devenir de los tiempos.

Es fácil deducir que a estos moralistas les afectaba un temor ante la pérdida de autoridad unidireccional y ante la potencial apertura a la posibilidad de una interpretación más libre y a un cuestionamiento por parte de los fieles de los preceptos emanados de la jerarquía a la que pertenecían. Para colmo, suponía darle la razón a la Iglesia protestante, que ya había experimentado un giro en su doctrina sobre el control de la natalidad en 1930. "¿Y acaso deberíamos admitir ahora que la Iglesia se ha equivocado en su cometido y que el Espíritu Santo asiste más a la Iglesia anglicana?”, se preguntaban $^{63}$.

Este documento inmovilista fue conocido como el minority report, el informe de la minoría, que se oponía al que se bautizó como majority report, aprobado por una abrumadora mayoría ${ }^{64}$. Ambos documentos eran confidenciales y estaban pensados para asistir al papa en su decisión final. Sin embargo, se filtraron a la prensa y se difundieron mundialmente, incrementando las expectativas de que efectivamente iba a producirse

\footnotetext{
${ }^{61}$ Ibidem., 48.

${ }^{62}$ Ibidem., 94.

${ }^{63}$ Ibidem., 100-101.

${ }^{64}$ Alana Harris, ed., The Schism of '68...
} 
MónICA GaRCÍA FERNÁNDEZ

Sexualidad y religión en el tardofranquismo. La recepción de la Humanae Vitae en España y la crisis de autoridad de la Iglesia

una liberalización de las enseñanzas de la Iglesia en materia de control de la natalidad. Además de comentarios en revistas, en España se publicaron varias ediciones de los informes provisionales sin autorización eclesiástica, lo que les valió a los editores alguna llamada de atención ${ }^{65}$. Uno de los divulgadores de los documentos en nuestro país fue Alfonso C. Comín, conocido por su militancia comunista y por ser partidario de una unión entre cristianismo y marxismo. Publicado en la editorial Nova Terra, Comín hacía un comentario favorable a las conclusiones del informe de la mayoría.

Resumiendo, las posiciones en términos sencillos podríamos decir que la mayoría considera a los cónyuges ante todo como personas y todos sus actos esencialmente como actos personales, mientras que la minoría da en todo momento la sensación de considerar a la pareja humana que se une a través del amor sexual como próxima a la pareja animal reproductora, muy lejos del hombre creado a imagen y semejanza de Dios ${ }^{66}$.

Así, acusaba a la minoría conservadora de dar una visión estática de la sexualidad que no tenía en cuenta ni el progreso de las ciencias, ni la evolución histórica. Como argumento en favor de una renovación, se refería también a la crisis generacional y a las nuevas ideas que se estaban difundiendo entre los jóvenes, quienes tendían a oponerse al autoritarismo retrógrado de sus mayores. Como temía el autor, una actitud reaccionaria de la Iglesia solo les empujaría lejos de la religión ${ }^{67}$.

\section{UNA DECISIÓN A CONTRACORRIENTE}

Si bien las conclusiones de la comisión pontificia pronosticaban un cambio dentro del magisterio de la Iglesia, esto no fue lo que ocurrió. Desoyendo las recomendaciones de la mayoría, Pablo VI hizo pública la encíclica Humanae vitae en julio de 1968, en la que de nuevo condenaba los llamados medios "artificiales" de

\footnotetext{
65 Alfonso C. Comín, ed., Control y regulación de nacimientos...; Julián Gómez del Castillo, Informe sobre el control de natalidad (Madrid: Zyx, 1967); José María Javierre, José Luis Martín Descalzo, Antonio Aradillas y José de Salazar, Control de natalidad. Informe para expertos. Los documentos de Roma (Madrid: Alameda, 1967); "El 'dossier' de Roma”, El Ciervo, noviembre de 1967, 4-5; "El dossier de Roma”, Triunfo, 25 de noviembre de 1967. El arzobispado de Madrid-Alcalá publicó una nota prohibiendo la difusión de los documentos de la comisión pontificia. Véase Ildefonso Adeva, "Literatura teológica española sobre moralidad matrimonial desde 1960 hasta la encíclica Humanae vitae", Scripta Theologica, 1, 2 (1969): 507-537.

${ }^{66}$ Alfonso C. Comín, Control y regulación de nacimientos..., 12.

${ }^{67}$ Ibídem., 26.
} 
control de la natalidad. Aunque el documento no recuperaba la jerarquización de los fines del matrimonio, alegaba que el significado unitivo y el procreador no podían separarse. Por tanto, las relaciones sexuales debían estar siempre abiertas a la posibilidad de trasmitir vida y la paternidad responsable solo podía ejercerse a través del método de la continencia periódica.

Sin embargo, no por ello se puso fin a la controversia sobre el control de la natalidad. La Humanae vitae levantó mucha polémica y oposición internacional y, al contrario de lo que había ocurrido con otros dictámenes del Vaticano, no siempre fue aceptada sin reservas por parte de las jerarquías eclesiásticas nacionales y otros miembros prominentes de la Iglesia. No faltaron quienes lamentaron una decisión a contracorriente de los tiempos que solo alejaría a los fieles de la fe y temieron que se convirtiera en un nuevo "caso Galileo". Muchos se dieron cuenta de que, no solo se basaba en una teología anticuada, sino que sería sistemáticamente trasgredida y quebrantada, poniendo en riesgo la credibilidad de la Iglesia. Otros la interpretaron como un abuso de autoridad por parte del papa, que rompía con el espíritu colegial del Concilio, sobre todo teniendo en cuenta que la mayor parte de la comisión pontificia había llamado a una renovación ${ }^{68}$.

Algunos teólogos y obispos renombrados mostraron públicamente su respetuosa disconformidad con algunos de los puntos de la encíclica. Además, las conferencias episcopales de países como Alemania, Bélgica o Inglaterra, entre otros, publicaron cartas pastorales en las que manifestaban su obligada adhesión, pero también aportaban una interpretación más laxa del documento que reducía su carácter obligatorio. Si bien en teoría se acataban las enseñanzas del Vaticano, muchos aseguraron que no se trataba de un documento infalible y que, por tanto, no era definitivo y podía ser reformado. También se predicó una actitud flexible y comprensiva para aquellos cristianos sinceros que intentaran seguir los mandatos de la encíclica, pero que en última instancia no pudieran cumplir algunos de sus puntos. Así, se hizo hincapié en la conciencia

\footnotetext{
${ }^{68}$ Alana Harris, ed., The Schism of '68...; Karina A. Felitti, "Iglesia católica y el control de la natalidad en tiempos del Concilio: La recepción de la encíclica Humanae vitae (1968) en Argentina", Anuario IEHS, 22 (2007): 349-372; VVAA, "Problemas teológicos pastorales de la 'Humanae Vitae"”, Iglesia Viva, 1920 (1969); Ofa Bezunartea, Condena y defensa de la píldora. Controversia mundial en torno a la Humanae vitae (Vizcaya: Editorial La Gran Enciclopedia Vasca, 1968); Manuel Useros, ¿Qué hacer con la "Humanae vitae"?: reflexiones para sacerdotes y seglares (Valencia: Comercial Editora de Publicaciones, 1969). El Ciervo publica varios artículos sobre el tema en su número 175-176 de septiembre-octubre de 1968.
} 
individual de los fieles como guía de sus decisiones, frente a una obediencia ciega, pasiva e irreflexiva en la autoridad ${ }^{69}$.

En definitiva, se matizaba la obligatoriedad de la encíclica. Quienes recurrieran a los anticonceptivos, no por egoísmo, sino porque su conciencia así lo recomendaba para poder conciliar las exigencias del amor conyugal y la paternidad responsable, podían ser disculpados si genuinamente buscaban vivir de acuerdo con la fe cristiana. De ese modo, se sugería que, aunque debía tenderse al ideal de perfección, era necesario comprender los fracasos y desviaciones, en función de las posibilidades y limitaciones que imponía la realidad cotidiana. Por tanto, no se negaba la encíclica, pero se relativizaba y se libraba de culpa a aquellos cristianos que por razones justificadas no pudieran obedecerla. Con ello se reconocía la falta de correspondencia entre la doctrina y la praxis, así como las dificultades de los creyentes para asimilar y aplicar con total precisión todos los aspectos de la doctrina plasmada en la encíclica de Pablo VI. No cabe duda de que se trataba de una actitud práctica ante el convencimiento de que muchos católicos se distanciarían de la Iglesia al comprobar que sus visiones y experiencias de la sexualidad y del amor eran incompatibles con el magisterio eclesiástico.

Ciertamente, la Humanae vitae provocó la decepción de muchos matrimonios católicos que se habían familiarizado con la píldora, cuya popularidad no había dejado de crecer durante aquellos años. Además, la demora en la decisión y la situación de ambigüedad e incertidumbre que ello había creado, unido al hecho de que la comisión pontificia encargada de estudiar el tema había decidido aprobar el control de la natalidad, contribuyeron a crear un clima de mayor aceptación del fármaco. Para autores como Hugh McLeod, este es un factor a tener en cuenta en la crisis religiosa de los años sesenta, si bien es difícil determinar en qué medida. Como señala este investigador, tras la Humanae vitae muchos católicos se sintieron cada vez más libres para ignorar las enseñanzas de la Iglesia y quienes permanecieron fieles a la misma reclamaron una mayor libertad para hacer sus propios juicios éticos en función de su conciencia ${ }^{70}$.

\footnotetext{
${ }^{69}$ Ibídem.

${ }^{70}$ Hugh McLeod, The Religious Crisis of the 1960s (Oxford University Press, 2010). Véanse también Dagmar Herzog, Sexuality in Europe. A Twentieth-Century History (Cambridge: Cambridge University Press, 2011), 133-175; Alana Harris, ed., The Schism of '68...; o David Geiringer, The Pope and the Pill...
} 
Algunas de las entrevistas realizadas para el proyecto Madres e hijas de la Transición española muestran precisamente el espíritu práctico que adoptaron muchas católicas a la hora de ignorar los criterios de la Iglesia en lo que se refiere al uso de anticonceptivos. Por ejemplo, una mujer nacida en 1948 hacía referencia al sentido común que prevalecía sobre el conflicto entre los sentimientos religiosos y los mandatos de la jerarquía con relación a la sexualidad.

Ese tema estaba en guerra con la religión. Es decir, si tú tenías un problema y no querías tener más hijos, tus ideas religiosas luchaban contra esas otras y al final, ¿cuáles ganan? Pues al final gana [...] el sentido común. Si yo tengo un hijo y tengo una infección de orina y el médico me dice "no te conviene que tengas más hijos", pues llegas a la conclusión de que "iDios mio!: supongo que me comprenderás que, en mi caso, no me conviene porque tengo esta enfermedad, ¿no?”. O "porque tengo este problema". Y poquito a poco ibas entrando... El médico, si era un buen ginecólogo, te decía: "Mira hija, como... yo creo que Dios no se va a enfadar porque usemos esto porque es lo que necesitas, no puedes tener más hijos". Y entonces ibas entrando por el DIU, por la pildora ${ }^{71}$.

Para otra mujer nacida en 1945 "la lógica" debía estar por encima de cualquier otra consideración, a pesar de que ella se declaraba "católica, apostólica, romana y practicante". Ante las dificultades para conseguir preservativos en una farmacia, los obtenían a través de una cuñada que trabajaba en el mundo farmacéutico.

[...] en aquella época el preservativo era una cosa que era... estaba prohibido por la Iglesia y yo decía: "Dios mío de mi alma, pues que se acueste un cura con una mujer que tenga siete chiquillos, a ver qué es lo que va a hacer. Tendrá que ponerle remedio". O sea, cosas que la lógica... en mí la lógica estaba por encima de una serie de circunstancias ${ }^{72}$.

En otras ocasiones, algunas mujeres se encontraban con curas menos estrictos, e incluso abiertos a aceptar el control de la natalidad, de modo que decidían acogerse a aquella opinión que mejor servía a sus intereses, pudiendo así seguir confiando en su fe. Este era el caso de una mujer que se iba a otro pueblo a confesarse, porque el de su parroquia siempre la amonestaba por usar anticonceptivos ${ }^{73}$. Otra recuerda a un cura

\footnotetext{
${ }^{71}$ Mujer nacida en 1948. Entrevista realizada para el Archivo audiovisual: Mujer y memoria. Madres e hijas de la Transición española. Cód. CVM-21 [Cinta 27], https://mujerymemoria.org

${ }^{72}$ Mujer nacida en 1945. Ibídem., Cód. CLC-25 [Cinta 32].

${ }^{73}$ Mujer nacida en 1948. Ibídem., Cód. MLAE-35 [Cinta 46].
} 
cuya opinión al respecto era que la sexualidad solo competía a los cónyuges, sin que nadie más pudiera inmiscuirse en sus decisiones.

Y este hombre, este cura, siempre hablaba y decía [...]: "En el dormitorio no se puede meter nadie más que el marido y la mujer y la decisión que se tome, que tomen ellos, es la decisión bien tomada. Ahí no puede entrar ni el papa ni el Vaticano ni nadie”. [...]

[...] Y esa educación venía de la Iglesia, o sea, de la Iglesia, a ver, de este cura que estaba totalmente apartado de los organismos normales. [...] Pero funcionaba muy bien en ese sentido porque él veía muy claro que una pareja tiene que funcionar como pareja y que [...] no tienes que meter a Dios por medio, [...] que son ellos los que tienen que ser responsables y tener los hijos que deban tener [...].

Pero ya en esa época este cura educaba en esa línea. Entonces, pues cuando decian: “iEl control de natalidad... pues es pecado! ¡Es pecado usar preservativos!” [...] y él decía que cada cual haga lo que le parezca y lo que quiera. [...]

Era fundamental: lo importante es el amor y lo importante es la... la relación y quererse ${ }^{74}$.

La prensa española no tardó en hacerse eco de la decisión de Pablo VI, publicándose numerosísimos libros y artículos comentando la encíclica ${ }^{75}$. Revistas como Ecclesia manifestaron su adhesión, al igual que otras más populares como Telva, Ama o Mundo Cristiano. Estas alabaron la encíclica e insistieron en que no había que interpretarla como un "no a la píldora", sino como un "sí al amor", " La directora de Telva, Pilar Salcedo, bautizaba la Humanae vitae como "la encíclica del amor". "E1 amor que no corre ese alto riesgo — afirmaba—, que no quiere expresarse, concretarse en nuevos latidos, no es amor. Es otra cosa que se llama placer"77. Siguiendo el documento pontificio, aseguraba que las píldoras anticonceptivas traerían como consecuencia una degradación de la mujer, que sería tratada como mero instrumento de placer y no como amada compañera. Con todo, las secciones de cartas del público de estas revistas también dan buena cuenta de la decepción y dudas que había causado entre los fieles. Así lo muestra una opinión de una lectora de Mundo Cristiano.

Soy de la generación que al terminar la guerra se alistó y trabajó de corazón en las filas de [Acción Católica], con un

\footnotetext{
${ }^{74}$ Mujer nacida en 1946. Ibídem., Cód. CCC-37 [Cinta 49].

${ }^{75}$ Agata Ignaciuk y Teresa Ortiz, Anticoncepción, mujeres y género...

${ }^{76}$ Pilar Salcedo, "La encíclica del amor", Telva, 15 de agosto de 1968; "Verdades a medias sobre la Humanae vitae", Mundo Cristiano, noviembre de 1968; Fernando Guerrero, "En torno a la Encíclica 'Humanae vitae'. Pablo VI defiende el amor y la vida", Ecclesia, 10 de agosto de 1968.

${ }^{77}$ Pilar Salcedo, "La encíclica del amor", Telva, 15 de agosto de 1968.
} 
entusiasmo que no permitía ver faltas ni poner en tela de juicio nada de lo que decidía la jerarquía. [...]

Francamente, yo esperaba que el Papa diera una solución mucho más al alcance de todos. Yo pienso que de la forma que está la vida ahora, hay motivos razonables para limitar el número de hijos.

En cuanto al Papa, yo le quiero mucho y tengo mucha confianza en él, pero no puedo dejar mi pena: no encuentro explicación convincente para su decisión ${ }^{78}$.

Otra carta enviada al consultorio de la revista femenina Ama revelaba la difusión de las ideas críticas que circulaban por Europa y que relativizaban la obligatoriedad de la encíclica.

Ayer, en una reunión de matrimonios, pasé un rato muy malo. Se empezó a comentar la "Humanae Vitae" y una persona que por su cultura y su profesión merece crédito dijo que esta, como todas las Encíclicas, admiten interpretaciones personales según la conciencia de cada uno.

Que cuando el Papa no habla "ex cathedra", es decir, de manera solemne, definiendo un dogma, su juicio no es infalible y no hay por qué acatarlo a raja tabla. Se citaron algunas opiniones de teólogos —según ellos, muy importantes- que defendian esta teoría ${ }^{79}$.

También en nuestro país se divulgaron las opiniones de aquellos moralistas que manifestaron una actitud discrepante con la encíclica y no faltaron quienes, aunque mostraron una respetuosa adhesión, difundieron una visión más abierta que hacía hincapié en la necesidad de abandonar una actitud de pasiva y servil obediencia, que enfatizaba la capacidad de los padres de familia para decidir de forma responsable y que subrayaba la importancia de la conciencia individual para interpretar la moral. Entre ellos destaca Enrique Miret Magdalena. Frente a quienes celebraban incondicionalmente la reafirmación de las doctrinas existentes, este autor planteaba algunas dudas y se hacía eco de los teólogos que cuestionaban la infalibilidad del papa y destacaban la capacidad de los seglares para reflexionar de forma autónoma. De ese modo, criticaba "un concepto infantil de obediencia ciega" e invita al análisis sereno de la encíclica ${ }^{80}$.

En la misma línea cabe mencionar la revista El Ciervo, que difundió algunos artículos de personalidades extranjeras que impugnaban la rigidez e inmovilismo de la

\footnotetext{
78 “Carta sobre la 'Humanae vitae”", Mundo Cristiano, enero de 1969.

${ }^{79}$ Ama, marzo de 1969.

${ }^{80}$ Enrique Miret Magdalena, "Una encíclica problemática”, Triunfo, 10 de agosto de 1968.
} 
Humanae vitae ${ }^{81}$. Además, publicó cartas de lectores en las que se mostraba la decepción que había causado la encíclica. En "Las reflexiones de un matrimonio joven”, una pareja católica valenciana refutaba algunos de los puntos utilizados por Pablo VI para oponerse al control de la natalidad. Igualmente, llamaba la atención sobre la inseguridad del método Ogino y sobre el silencio del papa durante años, lo que había obligado a los fieles a tomar las decisiones que en conciencia consideraron adecuadas. Asimismo, recordaba que la mayoría de la comisión pontificia había votado a favor de una renovación y desmentía que los anticonceptivos fueran a provocar un aumento de la inmoralidad y la infidelidad. Al contrario, afirmaba que la tranquilidad que aportaría la píldora sería un refuerzo de la armonía conyugal, al evitar que los maridos salieran a buscar satisfacción fuera del hogar. Por ello, consideraban que la encíclica había "supuesto un paso atrás en la evolución del pensamiento de la Iglesia sobre el matrimonio, motivado [...] por una revalorización de la concepción agustiniana de la naturaleza, que parecía definitivamente superada”. Del mismo modo, cuestionaban que las píldoras fueran juzgadas como medios antinaturales mientras que, por ejemplo, los trasplantes de corazón no lo eran, a pesar de que igualmente intervenían sobre la biología ${ }^{82}$.

La misma revista publicaba la carta de un padre de cinco hijos con sus objeciones a la encíclica. Tal y como alegaba, el seglar seguía "siendo considerado por la Jerarquía como un 'menor de edad' a pesar de que el Concilio nos dio a entender lo contrario". Finalmente, se preguntaba hasta qué punto el católico estaba obligado a cumplir una ley que, en conciencia, creía injusta ${ }^{83}$.

La recepción de la Humanae vitae refleja así una crisis en la soberanía intransigente de la Iglesia. Por un lado, se rechazaba la infalibilidad del sumo pontífice y de sus documentos y se abría la posibilidad para la renovación y adaptación a los tiempos. Por otro, se criticaba la actuación unilateral del papa y se reclamaba una mayor capacidad de los seglares para reinterpretar las enseñanzas en función de su conciencia, aunque esta debiera estar guiada por las recomendaciones de la jerarquía. De ese modo, la concepción unilateral de las normativas daba paso a una óptica que hacía hincapié en

\footnotetext{
81 Véanse los distintos artículos de El Ciervo en su número 175-176 de septiembre-octubre de 1968; también Rosario Bofill, "Review: Una encíclica a examen”, El Ciervo, septiembre de 1970, 15.

${ }^{82}$ M. T. Franch y V. Abad, "Las reflexiones de un matrimonio joven", El Ciervo, septiembre-octubre de 1968, 11.

${ }^{83}$ José Luis Martínez, “A veces me pregunto”, El Ciervo, septiembre-octubre 1968, 9.
} 
la necesidad de que existiera un mayor consenso, diálogo y autoridad compartida entre la Iglesia y sus fieles. Así lo planteaba Enrique Miret Magdalena en Triunfo.

Se abre, con ello, camino no a la rebelión, sino a un nuevo y muy tradicional concepto de autoridad en la Iglesia. Porque ya no cuenta entre los creyentes, en primer lugar, la fuerza jurídica o coercitiva del que manda [...]. La autoridad se recomienda a sí misma, no imponiéndose, sino persuadiendo; [...] tratando a los gobernados como asociados y colaboradores, en vez de súbditos... El autoritarismo resulta completamente extraño en cada una de las páginas del Nuevo Testamento ${ }^{84}$.

Además, no pocos llamaban la atención sobre el alejamiento que se produciría por parte de los creyentes. Así lo aseguraba Lidia Falcón en una encuesta publicada en La Vanguardia. "La Iglesia misma - afirmaba - puede verse abocada a un distanciamiento cada vez mayor entre los fieles y su jerarquía. Para el católico consecuente y practicante, la carga que acaba de echársele sobre los hombros le resulta

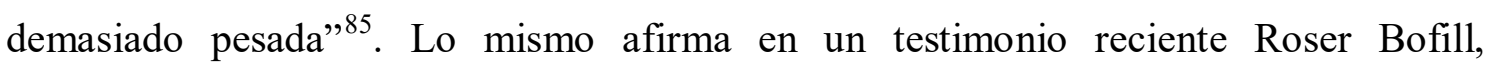
periodista católica de El Ciervo, recordando aquella encíclica como una gran decepción que obligó a muchos cristianos a abandonar la fe.

La gran decepció va ser aquella encíclica [...]. Allò va ser fatal, fatal. Perquè després del Concili esperàvem que la gent té la seva consciència [...] Molta gent va deixar el cristianisme per aixo ${ }^{86}$.

Según señala Teresa Rodríguez de Lecea, la publicación de la Humanae vitae marcó una interrupción del itinerario aperturista iniciado por Juan XXIII, así como una ruptura "de las buenas relaciones entre los cristianos de pensamiento progresista y la jerarquía de la Iglesia Católica" ${ }^{87}$. Como afirma otro historiador, este es un hito que señala "el punto de inflexión entre la euforia conciliar y el desencanto" ${ }^{\text {" }}$. También resultó decepcionante para algunas mujeres católicas de nuestro país, como María Salas, Pilar Bellosillo o la ya mencionada Roser Bofill, que vieron como las esperanzas de una

\footnotetext{
${ }^{84}$ Enrique Miret Magdalena, "Una encíclica problemática”, Triunfo, 10 de agosto de 1968.

${ }^{85}$ Lidia Falcón, "La trascendencia de la encíclica 'Humanae vitae", La Vanguardia, 3 de septiembre de $1968,15$.

86 Oriol Porta, dir., L'Església rebel (TVC Televisió de Catalunya, 2012), https://www.ccma.cat/tv3/alacarta/programa/LEsglesia-rebel/video/4128430

${ }^{87}$ Teresa Rodríguez de Lecea, "Mujer y pensamiento religioso en el franquismo", Ayer, 17 (1995): 177; Pilar Bellosillo, "La mujer en la Iglesia", coord. por Joaquín Ruiz-Giménez y Pilar Bellosillo, El concilio del siglo XXI (Madrid: PPC, 1987).

${ }^{88}$ Francisco Martínez Hoyos, "Mayo del 68 y los católicos catalanes", Hispania Sacra, 65, 131 (2013): 427, doi: https://doi.org/10.3989/hs.2013.013
} 
mayor igualdad de las mujeres en la Iglesia quedaban frustradas. Sin embargo, las mujeres siguieron reclamando sus derechos, cada vez con más fuerza. En 1968, Carmen Alcalde recogía en Diario Femenino recortes de prensa contra la encíclica y reivindicaba una mayor participación femenina en un debate que las afectaba a ellas preferentemente $^{89}$. Este mismo año, el Movimiento Democrático de Mujeres publicaba un programa en el que declaraba que solo al matrimonio le correspondía decidir con total libertad el número de hijos que quería tener, así como los medios para lograrlo, sin ser coaccionado por ninguna autoridad médica, civil o eclesiástica ${ }^{90}$. Como es sabido, el derecho a la libre utilización de anticonceptivos estuvo, junto con la despenalización del aborto y la aprobación del divorcio, entre las principales demandas feministas de la Transición, una lucha a la que también se adhirieron muchas católicas comprometidas con la igualdad y la democracia ${ }^{91}$.

\section{CONCLUSIONES}

La Humanae vitae causó un gran revuelo, convirtiéndose en un factor de secularización y de alejamiento de la ortodoxia católica, un proceso que ha de entenderse, en general, en el contexto de un cambio significativo en el lenguaje utilizado para hablar de la sexualidad. Donde antes se insistía en la procreación como su fin principal, pasa ahora a enfatizarse su valor afectivo en la pareja heterosexual. Asimismo, quienes eran partidarios de un cambio admitían el carácter histórico, cultural y variable de la moral, frente a quienes continuaban reclamando que se trataba de una ley natural, divina e inmutable. En ese sentido, se matizaba la distinción entre lo natural y lo antinatural, una dicotomía que tradicionalmente había servido para oponerse al control de la natalidad.

Estos debates son una muestra más de la disidencia cultural e intelectual del tardofranquismo, en la medida en que editoriales y revistas progresistas fueron interlocutoras de estos cambios, pero además también estaba en juego el propio

\footnotetext{
${ }^{89}$ Carmen Alcalde, “'Humanae Vitae': tres meses de polémica”, Diario Femenino, 31 de octubre de 1968.

${ }^{90}$ Mónica Moreno Seco, ed., Manifiestos feministas. Antología de textos del movimiento feminista español (1965-1985) (Universidad de Alicante, 2005), 41-42.

${ }^{91}$ Mónica Moreno Seco, "Mujeres en la transición de la Iglesia hacia la democracia: avances y dificultades", Historia del Presente, 10, 2 (2007): 25-40.
} 
MónICA García Fernández

Sexualidad y religión en el tardofranquismo. La recepción de la Humanae Vitae en España y la crisis de autoridad de la Iglesia

entendimiento del poder y la autoridad. La credibilidad de la Iglesia y su capacidad para ejercer una autoridad moral sobre la población fueron puestas en duda. Así, frente a una obediencia ciega, pasiva e irreflexiva, se hizo hincapié en la conciencia y madurez de los seglares para emitir sus propios juicios éticos y para reclamar que se escucharan y tuvieran en cuenta sus opiniones y experiencias. De ese modo, se cuestiona la autoridad indiscutible y unilateral de las jerarquías, en favor de una construcción más colectiva del conocimiento y de las normas. En ese sentido, de la soberanía intransigente e infalible pasa a defenderse un mayor consenso, diálogo y autoridad compartida, lo que es significativo en un régimen dictatorial como el franquista, al difundir un entendimiento democrático que entraba en contradicción con el sistema político vigente. En definitiva, el contexto y recepción de la Humanae vitae, así como los debates en torno a la sexualidad y el control de la natalidad son elementos interesantes para entender el proceso de secularización, la crisis del nacionalcatolicismo y la deslegitimación de presupuestos que sostenían la dictadura, allanando por tanto el camino para la transición a la democracia.

\section{BIBLIOGRAFÍA}

Adeva, Ildefonso. "Literatura teológica española sobre moralidad matrimonial desde 1960 hasta la encíclica Humanae vitae". Scripta Theologica, 1, 2 (1969): 507537.

Alcalde, Carmen. “'Humanae Vitae': tres meses de polémica”. Diario Femenino, 31 de octubre de 1968.

Álvarez, Lilí. "El control de la natalidad". Cuadernos para el Diálogo, diciembre de 1964.

Bellosillo, Pilar. "La mujer en la Iglesia", en El concilio del siglo XXI, coord. por Joaquín Ruiz-Giménez y Pilar Bellosillo, 151-166. Madrid: PPC, 1987.

Bezunartea, Ofa. Condena y defensa de la píldora. Controversia mundial en torno a la Humanae vitae. Vizcaya: Editorial La Gran Enciclopedia Vasca, 1968.

Bofill, Rosario. "Review: Una encíclica a examen". El Ciervo, septiembre de 1970, 15.

Campo, Salustiano del. "Los médicos ante el problema de la limitación de la natalidad". Revista Española de la Opinión Pública, 1 (1965): 27-38.

Campo, Salustiano del y María del Mar Rodríguez-Brioso. "La gran transformación de la familia española durante la segunda mitad del siglo XX". Reis, 100 (2002): 103-165.

Comín, Alfonso C., ed. Control y regulación de nacimientos. El "dossier" de Roma. Barcelona: Nova Terra, 1967.

Cueva Merino, Julio de la. "La secularización tranquila. Procesos de secularización bajo el franquismo (1960-1975)". En Encrucijadas del cambio religioso en España. 
Secularización, cristianismo e islam, editado por Julio de la Cueva, Miguel Hernando de Larramendi y Ana I. Planet, 31-54. Granada: Comares, 2018.

Dios Fernández, Eider de. "Domesticidad y familia: Ambigüedad y contradicción en los modelos de feminidad en el franquismo". Feminismo/s, 23 (2014): 23-46, doi: http://dx.doi.org/10.14198/fem.2014.23.02

Díaz Garrido, María del Carmen. "Historia de una familia". Teresa, abril de 1966.

Díez Nicolás, Juan. "Status socioeconómico, religión y tamaño ideal de la familia urbana". Revista Española de la Opinión Pública, 2 (1965): 83-108.

Espina, Luis. "¿Cuántos hijos debe tener un matrimonio cristiano? Paternidad responsable o dimensión familiar de la regulación de nacimientos". Proyección, 56 (1967): 215-223.

Falcón, Lidia. "La trascendencia de la encíclica 'Humanae vitae"”. La Vanguardia, 3 de septiembre de 1968, 15.

Felitti, Karina A. "Iglesia católica y el control de la natalidad en tiempos del Concilio: La recepción de la encíclica Humanae vitae (1968) en Argentina". Anuario IEHS, 22 (2007): 349-372.

-- La revolución de la píldora: sexualidad y politica en los sesenta. Buenos Aires: Edhasa, 2012.

Foley, Deirdre. “'Too Many Children?' Family Planning and Humanae Vitae in Dublin, 1960-72". Irish Economic and Social History, 46, 1 (2019): 142-160, doi: https://doi.org/10.1177/0332489319880677

Franch, M. T. y V. Abad. "Las reflexiones de un matrimonio joven". El Ciervo, septiembre-octubre de 1968, 11.

Fuentes, Juan Francisco. "Prensa y política en el tardofranquismo (1962-1975). La rebelión de las élites". Cercles, 6 (2003): 12-32.

Fullat, Octavio. La sexualidad: carne y amor. Barcelona: Nova Terra, 1966.

-- "Excursión por el control de la natalidad". Índice, 207 (1966).

Fundación FOESSA. Informe sociológico sobre la situación social en España 1969. Madrid: Euramérica, 1970.

-- Estudios sociológicos sobre la situación social de España 1975. Madrid: Euramérica, 1976.

García Fernández, Mónica. “'Dos en una sola carne'. Matrimonio, amor y sexualidad en el franquismo (1939-1975)". Tesis doctoral, Universidad de Oviedo, 2019.

García Vicente, Juan y Bernard Häring. Regulación de nacimientos. Un problema familiar visto por un médico y un teólogo. Madrid: Editorial El Perpetuo Socorro, 1965.

Geiringer, David. The Pope and the Pill: Sex, Catholicism and Women in Post-War England. Manchester University Press, 2019.

Gómez del Castillo, Julián. Informe sobre el control de natalidad. Madrid: Zyx, 1967.

Gomis, Lorenzo. "Píldora y natalidad". El Ciervo, agosto-septiembre de 1964, 11.

Guerrero, Fernando. "En torno a la Encíclica 'Humanae vitae'. Pablo VI defiende el amor y la vida". Ecclesia, 10 de agosto de 1968.

Harris, Alana, ed. The Schism of '68: Catholicism, Contraception and Humanae Vitae in Europe, 1945-1975. Palgrave MacMillan, 2018.

Herzog, Dagmar. Sexuality in Europe. A Twentieth-Century History. Cambridge University Press, 2011.

Ignaciuk, Agata. "Love in the Time of El Generalísimo: Debates About the Pill in Spain Before and After Humanae Vitae". En The Schism of '68: Catholicism and 
Humanae Vitae in Europe, 1945-1975, editado por Alana Harris, 229-271. Palgrave MacMillan, 2018.

Ignaciuk, Agata y Laura Kelly. "Contraception and Catholicism in the Twentieth Century: Transnational Perspectives on Expert, Activism and Intimate Practices". Medical History, 64, 2 (2020): 163-172, doi: https://doi.org/10.1017/mdh.2020.1

Ignaciuk, Agata y Teresa Ortiz. Anticoncepción, mujeres y género. La "píldora" en España y Polonia (1960-1980). Madrid: La Catarata, 2016.

Ignaciuk, Agata y Alba Villén Jiménez. “UUna pequeña revolución sexual? Experiencias de sexualidad y anticoncepción de mujeres andaluzas entre los años cincuenta y ochenta del siglo XX". Dynamis, 38 (2018): 303-331, doi: https://dx.doi.org/10.4321/S0211-95362018000200002

Javierre, José María, José Luis Martín Descalzo, Antonio Aradillas y José de Salazar. Control de natalidad. Informe para expertos. Los documentos de Roma. Madrid: Alameda, 1967.

Leclercq, Jacques. ¿Matrimonio de amor, hoy? Bilbao: Desclée de Brouwer, 1968.

López Arévalo, Juan Ramón. Un problema matrimonial ¿cuándo es lícita la píldora? Madrid: Studium, 1967.

López Azpiarte, E. "Doctrina conciliar sobre la regulación de los nacimientos". Proyección, 56 (1967): 224-230.

López Caballero, A. "La sexualidad como lenguaje del amor". Proyección, 56 (1967): 209-215.

López Ibor, Juan José. El libro de la vida sexual. Barcelona: Dánae, 1968.

López Navarro, José. Matrimonio, natalidad, píldora. Madrid: Palabra, 1967.

Marks, Laura. Sexual Chemistry: A History of the Contraceptive Pill. Yale University Press, 2010.

Martínez, José Luis. “A veces me pregunto”. El Ciervo, septiembre-octubre 1968, 9.

Martínez de Lahidalga, José. "Exigencias de la castidad conyugal, en sus aplicaciones pastorales, despuntes de la Humanae vitae". Iglesia Viva, 19-20 (1969): 43-66.

Martínez Hoyos, Francisco. "Mayo del 68 y los católicos catalanes". Hispania Sacra, 65, 131 (2013): 425-445, doi: https://doi.org/10.3989/hs.2013.013

McLeod, Hugh. The Religious Crisis of the 1960s. Oxford University Press, 2010.

Miguel, Jesús M. de "Sociología de la población y control de la natalidad en España". Reis, 10 (1980): 15-47.

Miret Magdalena, Enrique. "La Iglesia y la natalidad". Triunfo, 11 de julio de 1964.

-- Los nuevos católicos. Barcelona: Nova Terra, 1966.

--“Píldora sí, píldora no". Triunfo, 17 de febrero de 1968.

--“Paternidad responsable". Triunfo, 24 de febrero de 1968.

--"Una encíclica problemática". Triunfo, 10 de agosto de 1968.

--“¿Otra vez la píldora?”. Triunfo, 14 de marzo de 1972.

--“Matrimonio y natalidad”. Triunfo, 15 de febrero de 1975.

Montero, Feliciano. "Intelectuales católicos, del colaboracionismo al antifranquismo". Historia del Presente, 5 (2005): 41-68.

-- La Iglesia: de la colaboración a la disidencia (1956-1975). Madrid: Ediciones Encuentro, 2009.

Montero, Feliciano (coord.) 'El 'despegue' de la Iglesia”. Historia del Presente, 10, 2 (2007).

Morcillo, Aurora. En cuerpo y alma. Ser mujer en tiempos de Franco. Madrid: Siglo XXI, 2015. 
Moreno Seco, Mónica. "De la caridad al compromiso: las mujeres de Acción Católica (1958-1968)". Historia Contemporánea, 26 (2003): 239-265.

-- "Cristianas por el feminismo y la democracia. Catolicismo femenino y movilización en los años setenta". Historia Social, 53 (2005): 137-154.

-- ed. Manifiestos feministas. Antología de textos del movimiento feminista español (1965-1985). Universidad de Alicante, 2005.

-- "Mujeres en la transición de la Iglesia hacia la democracia: avances y dificultades". Historia del Presente, 10, 2 (2007): 25-40.

-- "Mujeres de Acción Católica y el Opus Dei. Identidades de género y culturas políticas en el catolicismo de los años sesenta". Historia y Política, 28 (2012): 167-194.

Muñoz Soro, Javier. "Intelectuales, revistas y editoriales en la crisis del franquismo: el caso de Cuadernos para el Diálogo y Edicusa (1963-1975)". Trocadero, 18 (2006): 23-44.

Oriol Porta, dir. L'Església rebel. TVC Televisió de Catalunya, 2012, https://www.ccma.cat/tv3/alacarta/programa/LEsglesia-rebel/video/4128430

Ortiz-Gómez, Teresa y Agata Ignaciuk. "The Fight for Family Planning in Spain during Late Francoism and the Transition to Democracy, 1965-1979". Journal of Women's History, 30, 2 (2018): 38-62, https://doi.org/10.1353/jowh.2018.0013

Ortiz Heras, Manuel y Damián A. González, coords. De la cruzada al desenganche. Madrid: Sílex Ediciones, 2011.

Pablo VI. Constitución pastoral Gaudium et spes sobre la Iglesia en el mundo actual. 7 de diciembre

1965 , http://www.vatican.va/archive/hist councils/ii vatican council/documents/vatii_const_19651207 gaudium-et-spes_sp.html

Peinador Navarro, Antonio. Los hijos ¿para qué? Razones y dificultades para una procreación regulada. Madrid: Coculsa, 1968.

Peláez Redondo, J. "El control de la natalidad: testimonio de un médico". Cuadernos para el Diálogo, diciembre de 1966.

Pérez-Agote, Alfonso. Cambio religioso en España: los avatares de la secularización. Madrid: Centro de Investigaciones Sociológicas, 2012.

Pío XI. Carta encíclica Casti connubii sobre el matrimonio cristiano. 31 de diciembre de 1930, https://w2.vatican.va/content/pius-xi/es/encyclicals/documents/hf_pxi enc 19301231 casti-connubii.html

Rakoczy, Susan. "A Gendered Critique of the Catholic Church's Teaching on Marriage and the Family: 1965-2016". Scriptura, 116 (2016): 1-19.

Rodríguez de Lecea, Teresa. "Mujer y pensamiento religioso en el franquismo". Ayer, 17 (1995): 173-200.

Rodríguez López, Sofía. "Las mujeres del Opus Dei (1930-1980): Género, clase y fe". Hispania Nova, 18 (2020): 551-598.

Rodríguez-Ocaña, Esteban, Agata Ignaciuk y Teresa Ortiz. "Ovulostáticos y anticonceptivos: El conocimiento médico sobre 'la píldora' en España durante el franquismo y la transición democrática (1940-1979)". Dynamis, 32, 2 (2012): 467-494, doi: http://dx.doi.org/10.4321/S0211-95362012000200009

Rojas Claros, Francisco. "Poder, disidencia editorial y cambio cultural en la España de los años sesenta". Pasado y Memoria, 5 (2006): 59-80.

Salcedo, Pilar. "La encíclica del amor". Telva, 15 de agosto de 1968. 
Tibau, Narciso. "Paternidad responsable. Expresión nueva en el magisterio de la Iglesia". Ecclesia, 26 de marzo de 1966.

Useros, Manuel. ¿Qué hacer con la "Humanae vitae" ?: reflexiones para sacerdotes y seglares. Valencia: Comercial Editora de Publicaciones, 1969.

Vilaltella Gran, Juan. "El sentido de la sexualidad". Cromosoma X, 35 (1969): 22-30.

VVAA. "Matrimonio y concilio". Proyección, 56 (1967): 195-230.

VVAA. "Problemas teológicos pastorales de la 'Humanae Vitae". Iglesia Viva, 19-20 (1969). 